\title{
Association of anti-smoking legislation with rates of hospital admission for cardiovascular and respiratory conditions
}

\author{
Alisa Naiman MHSc MD, Richard H. Glazier MD MPH, Rahim Moineddin PhD
}

Previously published at www.cmaj.ca

$\infty$ See related commentary by Maryon-Davis, page 747

\section{ABSTRACT}

Background: Few studies have examined the impact of antismoking legislation on respiratory or cardiovascular conditions other than acute myocardial infarction. We studied rates of hospital admission attributable to three cardiovascular conditions (acute myocardial infarction, angina, and stroke) and three respiratory conditions (asthma, chronic obstructive pulmonary disease, and pneumonia or bronchitis) after the implementation of smoking bans.

Methods: We calculated crude rates of admission to hospital in Toronto, Ontario, from January 1996 (three years before the first phase of a smoking ban was implemented) to March 2006 (two years after the last phase was implemented. We used an autoregressive integrated movingaverage (ARIMA) model to test for a relation between smoking bans and admission rates. We compared our results with similar data from two Ontario municipalities that did not have smoking bans and with conditions (acute cholecystitis, bowel obstruction and appendicitis) that are not known to be related to second-hand smoke.

Results: Crude rates of admission to hospital because of cardiovascular conditions decreased by $39 \%$ (95\% Cl $38 \%$ $40 \%$ ) and admissions because of respiratory conditions decreased by $33 \%(95 \% \mathrm{Cl} 32 \%-34 \%)$ during the ban period affecting restaurant settings. No consistent reductions in these rates were evident after smoking bans affecting other settings. No significant reductions were observed in control cities or for control conditions.

Interpretation: Our results serve to expand the list of health outcomes that may be ameliorated by smoking bans. Further research is needed to establish the types of settings in which smoking bans are most effective. Our results lend legitimacy to efforts to further reduce public exposure to tobacco smoke.

$\mathrm{T}$ obacco use is the leading cause of preventable disease and death worldwide. ${ }^{1}$ In the United States, second-hand smoke causes over 3000 deaths from lung cancer and 46000 deaths from heart disease per year. ${ }^{2}$ Second-hand smoke, defined as involuntary exposure to a combination of diluted, side-stream cigarette smoke and exhaled smoke from smokers ${ }^{4}$ is the third leading cause of preventable poor health and premature death in the developed world. ${ }^{3}$ Research delineating the impact of smoke-free legislation on cardiovascular and respiratory outcomes could have an immense impact on public health, given that an estimated one billion people are expected to die during the 21st century as a result of tobacco-related disease.

Public health campaigns have been aimed at increasing awareness of the dangers of second-hand smoke, and many jurisdictions worldwide have enacted legislation to restrict smoking in public places and at work. ${ }^{6}$ A growing number of studies has shown evidence of reductions ranging from $8 \%$ to $40 \%$ in admissions to hospital for acute myocardial infarction after introduction of smoke-free legislation. ${ }^{7-13}$ Very few studies have examined the impact of anti-smoking legislation on other cardiovascular outcomes or on respiratory outcomes.

Our objective was to determine the effect of anti-smoking legislation on admissions to hospital for the cardiovascular conditions of acute myocardial infarction, angina and stroke, and the respiratory conditions of asthma, chronic obstructive pulmonary disease, and pneumonia or bronchitis.

\section{Methods}

\section{Study design and data sources}

Toronto is the provincial capital of Ontario, Canada, and has a population of about 2.5 million people, making it the fifth most populous municipality in North America. Eight percent of the total Canadian population resides in Toronto, and about $25 \%$ of new immigrants to the country settle in the city. In Ontario, smoke-free legislation was a municipal responsibility until the implementation of a comprehensive province-wide smoking ban in May 2006. ${ }^{14}$

Public smoking bans may take different forms, from full comprehensive smoking bans in all public places to partial bans where smoking is allowed in some public places (e.g., bars or restaurants) and under certain restrictions..$^{15}$

We obtained information about smoking restrictions in Toronto from the Toronto Public Health section of the website of the City of Toronto, which provides a historical record of smoke-free legislation in the city. Toronto passed bylaw no. 441-1999 ${ }^{16}$ requiring all public places and workplaces to

From the Institute for Clinical Evaluative Sciences (Naiman, Glazier, Moineddin); the Department of Family and Community Medicine (Naiman, Glazier Moineddin), University of Toronto; the Toronto East General Hospital (Naiman); St. Michael's Hospital (Glazier); and the Toronto Dalla Lana School of Public Health (Moineddin), University of Toronto, Toronto, Ont

CMAJ 2010. DOI:10.1503/cmaj.091130 
be smoke-free, and implemented it in three phases. The first phase, implemented in October 1999, required all public places and workplaces to be smoke-free. The second phase, implemented in June 2001, required all restaurants, dinner theatres and bowling centres, except for designated smoking rooms, to be smoke-free. The final stage of the ban, implemented in June 2004, required all bars, billiard halls, bingo halls, casinos and racetracks, except for designated rooms, to be smoke-free.

We examined the 15 largest Ontario municipalities (based on the 2006 Canadian Census). ${ }^{17}$ Two of these municipalities (Durham Region and Thunder Bay) had no public smoking restrictions until after the introduction of phase three of Toronto's anti-smoking legislation. ${ }^{18}$ These two were selected as control cities. Durham Region is a rapidly-growing area to the east of and adjacent to Toronto, whereas Thunder Bay is a regional centre in the northwest part of Ontario, far removed from Toronto. Demographic characteristics of Toronto, control cities and Canada were obtained from the 2006 Canadian Census $^{19}$ and the Canadian Community Health Survey. ${ }^{20}$ The 2005 public access version of the Canadian Community Health Survey file was used, and responses to questions about self-reported smoking, exposure to second-hand smoke and rates of influenza vaccination were identified.

We selected three cardiovascular conditions (acute myocardial infarction, angina and ischemic stroke) and three respiratory conditions (asthma, chronic obstructive pulmonary disease, and bronchitis or pneumonia). Currently, evidence is strongest for a relationship between smoking bans and rates of admission to hospital for acute myocardial infarction. However, a smaller number of studies has explored the impact of smoking bans on other ischemic conditions, including angina and stroke. We included respiratory conditions because evidence also exists for an association between

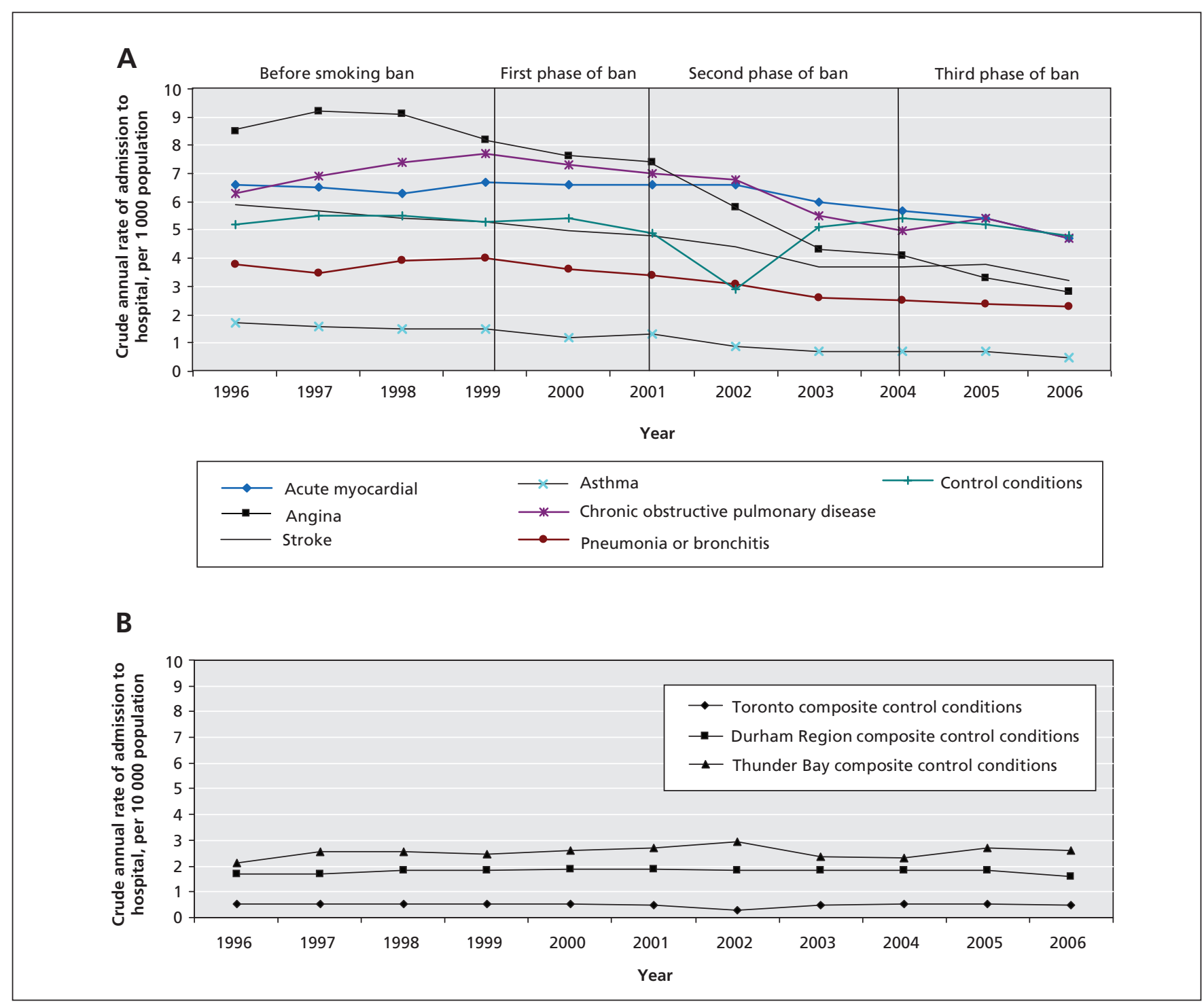

Figure 1: (A) Crude annual rates of admission to hospital attributable to cardiovascular and respiratory conditions and to control conditions in Toronto from 1996 to 2006. (B) Crude annual rates of admission to hospital for control conditions in Toronto and in control cities of Thunder Bay and Durham Region from 1996 to 2006. 
second-hand smoke and respiratory symptoms. ${ }^{21-25} \mathrm{We}$ selected the three most common respiratory conditions leading to hospital admissions.

In addition to selecting control cities, we selected acute cholecystitis, bowel obstruction and appendicitis as control conditions. Hospital admissions because of these conditions should be independent of any changes in smoking legislation, given that no known relationship exists between these conditions and smoke exposure.

The Discharge Abstract Database of the Canadian Institute for Health Information records discharge-related information on all patients admitted to acute-care hospitals in Ontario. We used the diagnostic codes of the International Classification of Diseases (ICD) 9 and 10 (Appendix 1, available at www.cmaj .ca/cgi/content/full/cmaj.091130/DC1) to identify the primary reason for hospital admission for cardiovascular, respiratory and control conditions in Toronto from January 1996 to April 2006. We also calculated number of admissions to hospital because of cardiovascular, respiratory and control conditions in control cities. Admissions because of cardiovascular and chronic obstructive pulmonary disease were limited to patients aged 45 years and older, and asthma admissions were limited to those younger than age 65 years. There were no age restrictions on admissions attributable to pneumonia or bronchitis or to control conditions.

We obtained population estimates for Toronto and control cities from the 1996, 2001 and 2006 censuses of Statistics Canada. ${ }^{17} \mathrm{We}$ used interpolation of population estimates between census years to create yearly population estimates.

\section{Statistical analysis}

We first calculated crude rates of hospital admission for acute myocardial infarction, composite cardiovascular conditions (acute myocardial infarction, angina, stroke) and composite respiratory conditions (asthma, chronic obstructive pulmonary disease, and pneumonia or bronchitis) outcomes. We then used an autoregressive integrated moving-average (ARIMA) model to isolate the effect of the smoking ban from existing time trends. A regression coefficient that quantifies the effect of the variable (smoking ban) was estimated (Appendix 2, available at www.cmaj.ca/cgi/content/full/cmaj .091130/DC1). We repeated these analyses for control municipalities and control conditions. Previous studies have found that risk for acute myocardial infarction decreases immediately after reductions in exposure to second-hand smoke..$^{7-10}$ Therefore, we tested for an immediate change in rates after implementation of ban legislation.

We performed subgroup analyses by age group and sex. Our study was approved by the research ethics board of Sunnybrook Health Sciences Centre.

\section{Results}

Crude annual rates of admission to hospital that were attributable to each cardiovascular and respiratory condition declined in Toronto during the 10-year period of our study (Figure 1a). The largest declines were seen after the phase of the ban affecting restaurants came into effect, and included a $17 \%$ (95\% CI 14\%-19\%) decrease in the crude rate of admission because of acute myocardial infarction, a 39\% (95\% CI 38\%$40 \%$ ) decrease in crude rates of admission because of cardiovascular conditions and a 33\% (95\% CI 32\%-34\%) decrease in rates of admission for respiratory conditions. Crude annual rates of admissions attributable to composite control conditions in Toronto and in control cities remained relatively stable during the 10-year period of the study (Figure 1b). Additional graphs showing crude annual rates of admissions in the control cities are available in Appendix 3, at www.cmaj.ca /cgi/content/full/cmaj.091130/DC1.

Demographic data for Toronto, the control cities and Canada are listed in Table 1. Toronto's population was similar to control cities in age, sex and socioeconomic characteristics, but a

Table 1: Demographic characteristics of the populations of Toronto, control cities and Canada at start of the study*

\begin{tabular}{|c|c|c|c|c|}
\hline \multirow[b]{2}{*}{ Characteristic } & \multirow[b]{2}{*}{ Toronto } & \multicolumn{2}{|c|}{ Control cities } & \multirow[b]{2}{*}{ Canada } \\
\hline & & Thunder Bay & Durham region & \\
\hline Male, \% & 48.2 & 48.4 & 48.9 & 49.0 \\
\hline Population $<20$ years old, $\%$ & 22.2 & 22.9 & 28.3 & 24.4 \\
\hline Individual income, median, \$ & 24544 & 27395 & 32005 & 25615 \\
\hline Foreign-born, \% & 49.9 & 10.8 & 20.3 & 19.8 \\
\hline Current smoker, \%†‡ & 18.1 & 26.6 & 24.8 & 21.7 \\
\hline Exposed to second-hand smoke, $\%+\S$ & 11.0 & 18.7 & 16.1 & 14.7 \\
\hline
\end{tabular}

*All data were obtained from the 2006 Statistics Canada Census ${ }^{19}$ unless otherwise noted.

tFrom the 2005 Canadian Community Health Survey. ${ }^{20}$

$\ddagger$ People aged 12 years and older who reported their smoking status and defined their current smoking status as smoking on a daily or occasional basis.

§Non-smoking people aged 12 years and older who were exposed to second-hand smoke on most days of the month preceding the survey.

t+People aged 12 years and older who reported when they had last received influenza vaccination. 


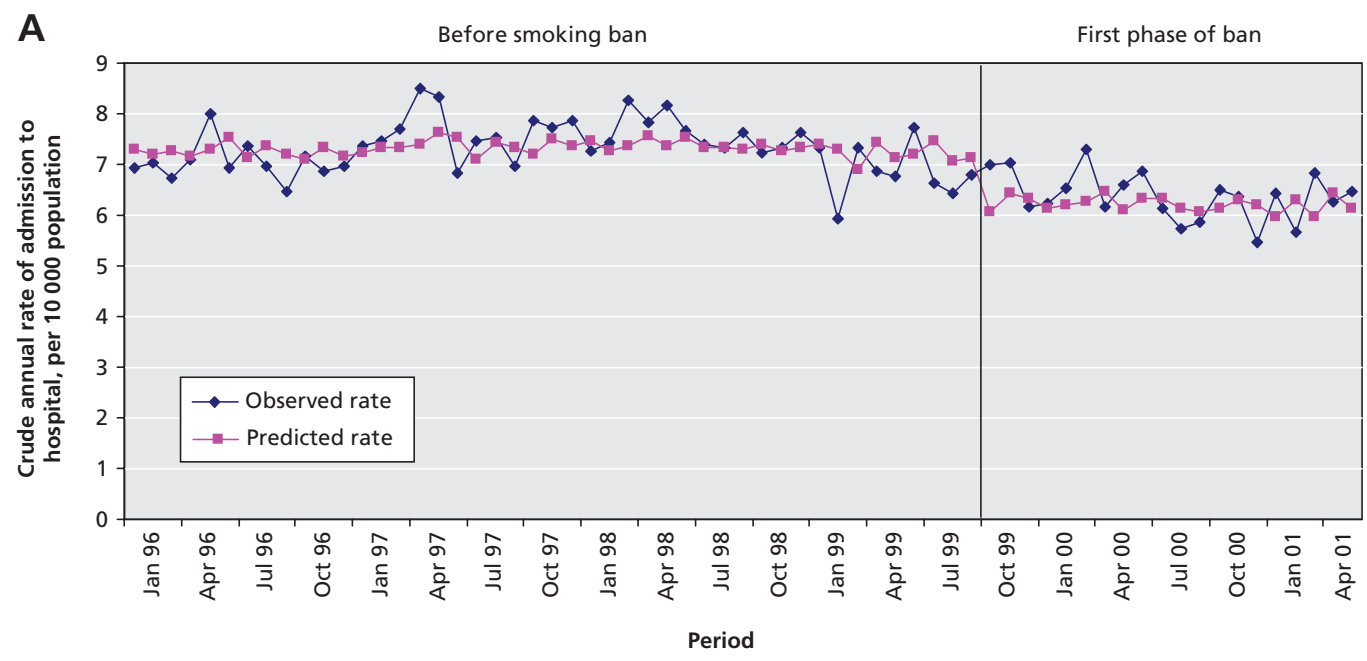

B First phase of ban Second phase of ban

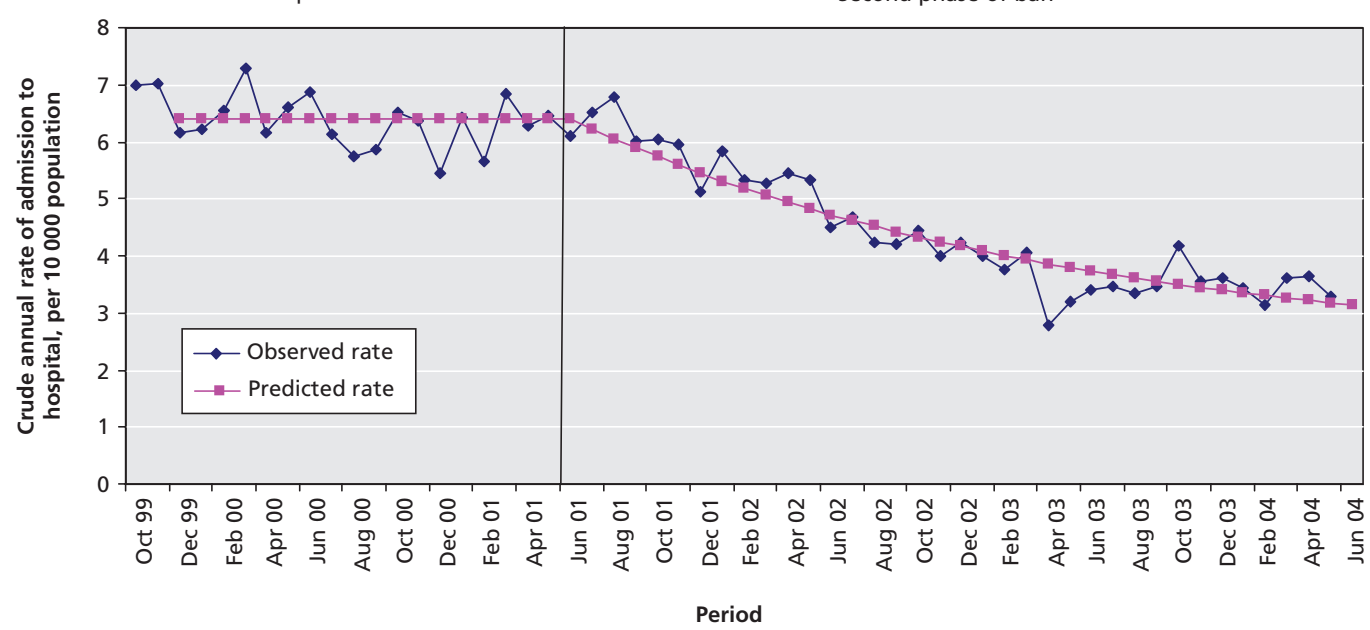

C

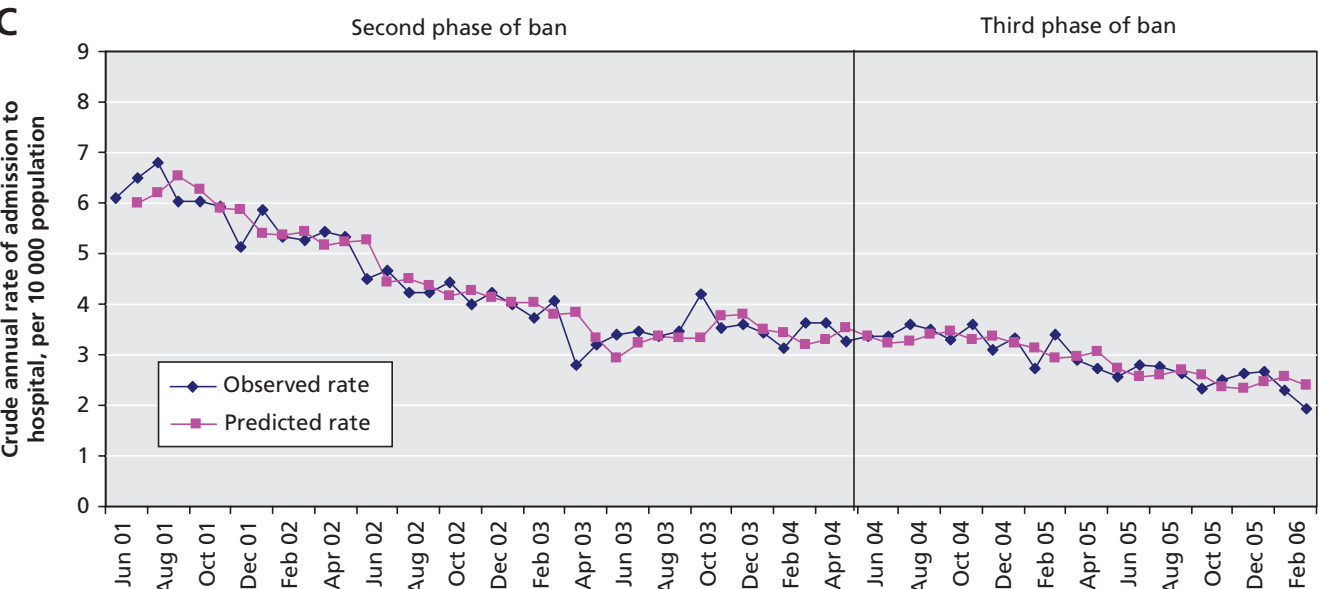

Period

Figure 2: Time-series analysis for angina during the three phases of the ban on smoking in Toronto. (A) First phase. (B) Second phase. (C) Third phase. 
much higher proportion of its population was foreign-born. Toronto also had slightly lower rates of smoking and exposure to second-hand smoke. The two control cities had similar rates of smoking and exposure to second-hand smoke compared with Toronto.

Each condition required an ARIMA model for each of the ban periods. The results for angina during the three periods of the smoking ban are presented in Figure 2. The results of the time-series analysis are summarized in Table 2. During the first phase of the ban's implementation, which affected public places and workplaces, there was a significant reduction in hospital admissions attributable to angina $(p<0.001)$ but not in admissions attributable to other conditions. A significant reduction in admissions was evident for all conditions after the introduction of the second phase of the ban, which included restaurants. Only acute myocardial infarction showed a significant decrease in number of hospital admissions after the introduction of the third and final phase of the ban compared with the previous time period. Results did not show consistently different findings for any particular age group or for either sex. No significant reductions were observed in number of hospital admissions attributable to control conditions during any of the Toronto ban periods (Table 2 ).

Table 2: Reduction in annual rates of admission to hospital for cardiovascular, respiratory and control conditions, per 10000 population

\begin{tabular}{|c|c|c|c|c|c|c|c|c|c|}
\hline \multirow{3}{*}{$\begin{array}{l}\text { Condition } \\
\text { AMI }\end{array}$} & \multicolumn{3}{|c|}{$\begin{array}{l}\text { Smoking ban in public places } \\
\text { and workplaces v. no ban }\end{array}$} & \multicolumn{3}{|c|}{$\begin{array}{c}\text { Smoking ban in restaurants } \\
\text { v. in public places and workplaces }\end{array}$} & \multicolumn{3}{|c|}{$\begin{array}{l}\text { Smoking ban in bars v. in } \\
\text { restaurants }\end{array}$} \\
\hline & \multicolumn{2}{|c|}{$\begin{array}{l}\text { Reduction in rate of } \\
\text { admission }(95 \% \mathrm{Cl})\end{array}$} & \multirow{2}{*}{$\begin{array}{r}p \text { value } \\
0.150\end{array}$} & \multicolumn{2}{|c|}{$\begin{array}{l}\text { Reduction in rate of } \\
\text { admission }(95 \% \mathrm{Cl})\end{array}$} & \multirow{2}{*}{$\begin{array}{c}p \text { value } \\
0.040\end{array}$} & \multicolumn{2}{|c|}{$\begin{array}{l}\text { Reduction in rate of } \\
\text { admission }(95 \% \mathrm{Cl})\end{array}$} & \multirow{2}{*}{$\frac{p \text { value }}{0.004}$} \\
\hline & 0.171 & $(-0.59$ to 0.40$)$ & & -0.477 & $(-0.95$ to -0.003$)$ & & -0.611 & $(-1.03$ to -0.19$)$ & \\
\hline Angina & -0.913 & $(-1.24$ to -0.59$)$ & $<0.001$ & -0.166 & $(-0.21$ to -0.12$)$ & $<0.001$ & 0.021 & $(-0.11$ to 0.15$)$ & 0.750 \\
\hline Asthma & -0.201 & (-0.42 to 0.02$)$ & 0.070 & -0.354 & $(-0.53$ to -0.018$)$ & $<0.001$ & -0.161 & $(-0.33$ to 0.008$)$ & 0.060 \\
\hline COPD & 0.433 & $(-0.33$ to 1.19$)$ & 0.260 & -1.040 & $(-1.81$ to -0.27$)$ & 0.008 & -0.748 & $(-1.56$ to 0.07$)$ & 0.070 \\
\hline $\begin{array}{l}\text { Lung } \\
\text { infection* }\end{array}$ & -0.152 & $(-0.44$ to 0.14$)$ & 0.300 & -0.598 & $(-0.98$ to -0.21$)$ & 0.002 & -0.408 & $(-0.90$ to 0.08$)$ & 0.100 \\
\hline Control & -0.003 & $(-0.03$ to 0.012$)$ & 0.750 & -0.004 & $(-0.03$ to 0.02$)$ & 0.680 & -0.030 & $(-0.03$ to 0.02$)$ & 0.830 \\
\hline
\end{tabular}

Note: $\mathrm{AMI}=$ acute myocardial infarction, $\mathrm{Cl}=$ confidence interval, $\mathrm{COPD}=$ chronic obstructive pulmonary disease, Control = acute cholecystitis, bowel obstruction and appendicitis.

* Lung infection refers to pneumonia or bronchitis.

Table 3: Reduction in annual rates of admission to hospital for control conditions, per 10000 population

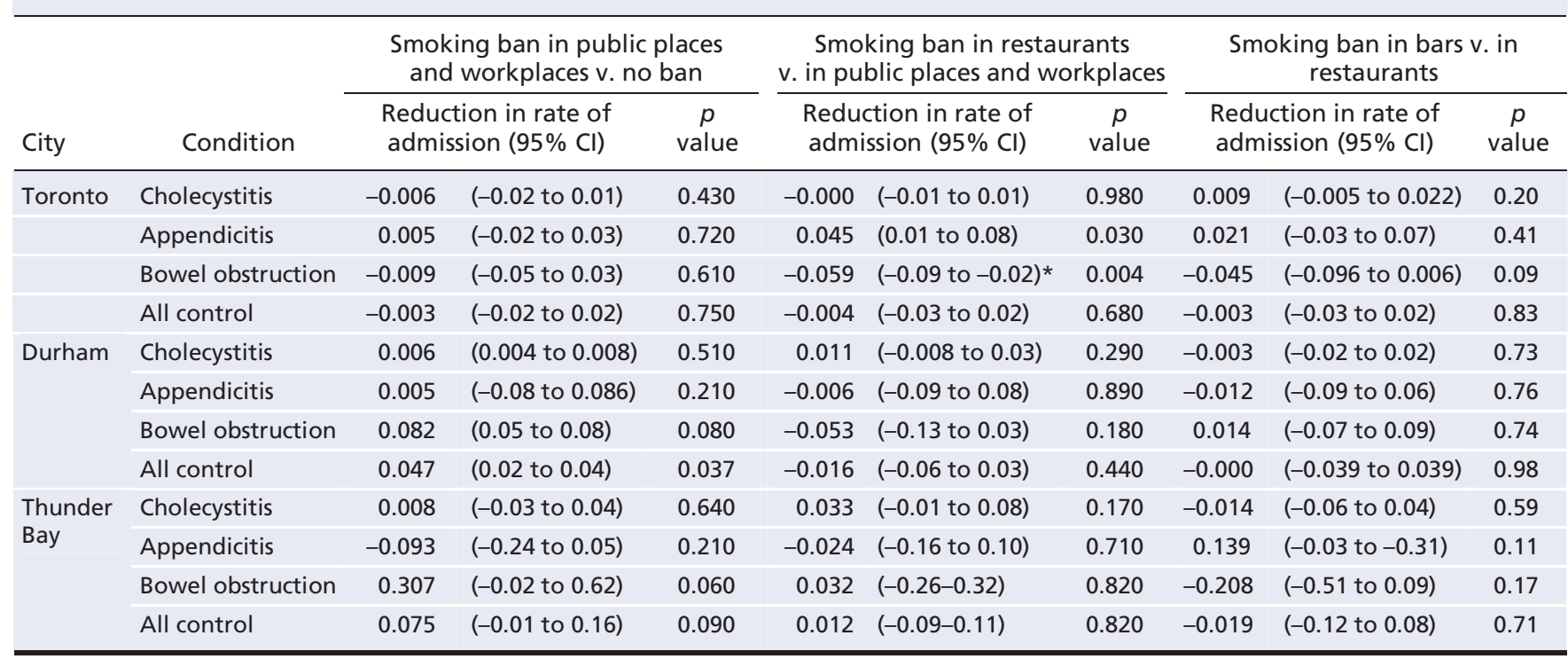

Note: $\mathrm{Cl}=$ confidence interval.

*Statistically significant at $p<0.004$. 
The results of the time-series analysis of data for control conditions in both control municipalities and in Toronto are summarized in Table 3. There were no significant reductions in hospital admissions in the composite control group (cholecystitis, bowel obstruction, appendicitis) for any area (i.e., Toronto or control cities) during the three periods of the ban. We observed a significant increase in hospital admissions because of bowel obstruction in Toronto during the second period of the ban. Results during the two other ban periods were not significant.

In control cities, we observed an increase of $14.6 \%$ in crude annual rates of admission for acute myocardial infarction during the second phase of the ban that affected restaurants, corresponding with a significant increase in the trend of rates of hospital admission before and after the ban $(p<0.001)$. There was a $3.4 \%$ overall reduction in hospital admissions for cardiovascular conditions $(p=0.055)$ and a $13.5 \%$ overall reduction in admissions for respiratory conditions $(p=0.239)$, corresponding with nonsignificant decreases in the trend of rates of hospital admission before and after the ban.

\section{Interpretation}

The implementation of anti-smoking legislation was associated with significant reductions both in hospital admissions attributable to cardiovascular conditions and those attributable to respiratory conditions. A consistent relation was evident between these reductions and a ban on smoking in restaurants. No significant changes were observed in hospital admissions attributable to control conditions in Toronto or in admissions because of cardiovascular and respiratory conditions in control cities during the second phase of the ban. The importance of restaurants in exposure to smoking may lie in their ubiquity and the frequency with which people dine out.

Compared with other studies, the smaller effect sizes in our study for rates of admission to hospital because of acute myocardial infarction may be related to both the stepwise enactment of anti-smoking legislation and lower rates of active smoking levels compared with other jurisdictions. Our study was conducted over a longer duration than most other studies, and hospital admissions were captured through a large, well-validated population database, allowing for better delineation of trends.

While complete isolation of one variable is not possible in an ecological study, the interrupted time-series design is able to evaluate both the immediate impact of a variable and its impact over time, while controlling for trends before the introduction of the variable. To further attempt to isolate the impact of smoking bans, we used two different strategies control conditions (i.e., gastrointestinal conditions) and control cities. The inclusion of control conditions addressed covariables specific to Toronto, whereas control cities accounted for province-wide secular trends. Previous studies have focused on the impact of public smoking restrictions on cardiovascular outcomes and, in particular, on acute myocardial infarction. ${ }^{7-9} \mathrm{Few}$, if any, studies to date have examined hospital admissions for respiratory conditions in association with the implementation of smoke-free legislation. Those studies that have focused on respiratory conditions were limited to exploring the relationship between a reduction in symptoms and the implementation of smoking bans.

\section{Limitations}

Our study should be interpreted in light of some limitations. Our results show a clear association between the implementation of a ban on smoking and admissions to hospital for cardiovascular and respiratory conditions, but it has not proven a causal relation. Ideally, a study concerned with the impact of second-hand smoke should be restricted to the non-smoking population. However, the ecological design of this study prevents the delineation of individual smoking status and other individual-level information, such as actual exposure to second-hand smoke and other risk factors (e.g., prior acute myocardial infarction and other comorbidities). This methodological limitation makes it possible that our observed decreases in both cardiovascular- and respiratoryrelated admissions to hospital were the result of active smokers smoking less or quitting. Although the purpose of smoking bans is to decrease exposure to second-hand smoke for non-smokers, such bans may also have an impact on active smoking.

However, Barone-Adesi and colleague ${ }^{26}$ observed an $11 \%$ reduction in admissions to hospital because of acute myocardial infarction during the first five months after the introduction of a smoking ban in Italy in January 2005, and calculated that the contribution of reduced active smoking to this reduction was less than $1 \%$, based on the observed reductions in smoking prevalence and mean number of cigarettes smoked and the relative risks for ischemic heart disease associated with active smoking.We therefore suggest that the reduction in hospital admissions observed in our study is unlikely to have resulted from decreased rates of smoking.

Finally, other factors that occurred over the period of our study (e.g., increases in taxes on tobacco, tightened restrictions on advertising, the addition of graphic warnings to cigarette packaging and removal of smoking-related products from point-of-sale display) may also have affected rates of admission to hospital by reducing smoking behaviour and episodes of smoking-related diseases. Smokers who chose after the ban not to frequent restaurants may have opted for more healthy behaviours or pastimes, which could have similarly affected rates of admission.

\section{Conclusion}

Legislated bans on smoking are associated with reduced rates of admission to hospital, reinforcing the value of such bans for public health. Our study suggests that such legislation is related to admissions for both cardiovascular and respiratory conditions. Our findings are consistent with the evidence that exposure to second-hand smoke is detrimental to health and legitimize legislative efforts to further reduce exposure. Further research is needed to establish the types of settings in which smoking bans are most effective.

This article has been peer reviewed.

Competing interests: None declared 
Contributors: All of the authors contributed to the design of the study, the acquisition and interpretation of the data and the critical revision of the manuscript. Alisa Naiman contributed to the conception of the study, drafted the manuscript and is guarantor of the data. Richard Glazier was involved in the supervision of the study. Rahim Moineddin conducted the statistical analyses of the data. All of the authors approved the final version of the manuscript submitted for publication.

Acknowledgements: The authors thank Doug Manuel, Therese Stukel and Don Redelmeier for their critical comments on earlier drafts of the manuscript.

Funding: This study was supported by the Institute for Clinical Evaluative Sciences (ICES), which is funded by an annual grant from the Ontario Ministry of Health and Long-Term Care (MOHLTC). The opinions, results and conclusions reported in this paper are those of the authors and are independent from the funding sources. No endorsement by ICES or the Ontario MOHLTC is intended or should be inferred. No external funding was received for this study.

\section{REFERENCES}

1. Koh HK, Joossens MA, Connolly G. Making smoking history worldwide. $N$ Engl J Med 2007;356:1496-8.

2. World Health Organization. WHO report on the global tobacco epidemic, 2009: implementing smoke-free environments. Geneva (Switzerland): The Organization; 2008 Available: www.who.int/tobacco/mpower/en/index.html (accessed 2009 Jan. 29).

3. Panagiotakos DB, Pitsavos C, Chrysohoou C, et al. Effect of exposure to secondhand smoke on markers of inflammation: the ATTICA Study. Am J Med 2004;116:145-50.

4. Nelson E. The miseries of passive smoking. Hum Exp Toxicol 2001;20:61-83

5. Teo KK, Ounpuu S, Hawken S, et al. Tobacco use and risk of myocardial infarction in 52 countries in the INTERHEART study: a case control study. Lance 2006;368:647-58

6. Perez CE. Second-hand smoke exposure: Who's at risk? Ottawa $(\mathrm{ON})$ : Statistics Canada; 2004. Available: http://www.statcan.gc.ca/studies-etudes/82-003 /archive/2004/7037-eng.pdf (accessed 2010 Feb. 8). Cat no. 82-003.

7. Sargent RP, Shepard RM, Glantz S. Reduced incidence of admissions for myocardial infarction associated with public smoking ban: before and after study. BMJ 2004;328:977-83.

8. Bartecchi C, Alsever RN, Nevin-Woods C, et al. Reduction in the incidence of acute myocardial infarction associated with a citywide smoking ordinance. Circulation 2006;114:1490-6.

9. Barone-Adesi F, Vizzini L, Merletti F, et al. Short-term effects of Italian smoking regulation on rates of hospital admission for acute myocardial infarction. Eur Heart J 2006;27:2468-72.

10. Khuder SA, Milz S, Jordan T, et al. The impact of a smoking ban on hospita admissions for coronary heart disease. Prev Med 2007;45:3-8.

11. Juster HR, Loomis MS, Hinman TM, et al. Declines in hospital admissions for acute myocardial infarction in New York state after implementation of a comprehensive smoking ban. Am J Public Health 2007;97:2035-9.

12. Cesaroni G, Forastiere F, Agabiti N, et al. Effect of the Italian smoking ban on population rates of acute coronary events. Circulation 2008;117:1183-8.

13. Pell JP, Haw S, Cobbs S, et al. Smoke-free legislation and hospitalizations for acute coronary syndrome. N Engl J Med 2008;359:482-91.

14. Smoke-Free Ontario. Protecting Ontarians from second-hand smoke. Toronto (ON): Ontario Ministry of Health Promotion; 2009 Available: www.mhp.gov.on .ca/English/health/smoke_free/default.asp (accessed 2010 Feb. 8).

15. The historical context of the evolution of smoke-free bylaws in Ontario. Toronto $(\mathrm{ON})$ : Ontario Campaign for Action on Tobacco. Available: www.ocat.org /onlegislation/context.html (accessed 2008 Feb. 29).

16. History of smoke-free legislation in Toronto. Toronto (ON): Toronto Public Health Backgrounder; 2006 Available: www.toronto.ca/health/smokefree/pdf /backgrounder_smokefree_history.pdf (accessed 2010 Feb. 28).

17. Population and dwelling counts, for Canada, provinces, and territories, 2006 and 2001 censuses - 100\% data. Ottawa (ON): Statistics Canada; 2008. Available: www12 .statcan.ca/english/census06/data/popdwell/Table.cfm (accessed 2008 Nov. 28).

18. Health Concerns - Ontario. Municipal by-laws: tobacco control. Ottawa (ON): Health Canada; 2008. Available: www.hc-sc.gc.ca/hc-ps/tobac-tabac/about-apropos /role/municip/on-eng.php (accessed 2010 Feb. 8)

19. 2006 Community profiles. Ottawa (ON): Statistics Canada; 2008. Available:
www12.statcan.ca/census-recensement/2006/dp-pd/prof/92-591/index.cfm?Lang=E (accessed 2010 Mar. 31)

20. Canadian Community Health Survey (CCHS), 2007, 2005 and 2003 CANSIM database [Table 105-0502]. Ottawa (ON): Statistics Canada; 2008. Available: http:// cansim2.statcan.gc.ca/cgi-win/cnsmcgi.pgm?regtkt=\&C2Sub=\&ARRAYID=1050502 $\& \mathrm{C} 2 \mathrm{DB}=\mathrm{PRD} \& \mathrm{VEC}=\& \mathrm{LANG}=\mathrm{E} \&$ SrchVer $=2 \&$ ChunkSize $=50 \&$ SDDSLOC $=\&$ ROOTDIR $=$ CII/\&RESULTTEMPLATE $=$ CII/CII_PICK\&ARRAY_PICK $=1 \&$ SDDSID $=\&$ SDDSDESC $=($ accessed 2010 Mar. 31 $)$.

21. Eisner MD, Smith AK, Blanc PD. Bartenders' respiratory health after establishment of smoke-free bars and taverns. JAMA 1998;280:1909-14.

22. Jindal SK, Gupta D, Singh A. Indices of morbidity and control of asthma in adult patients exposed to environmental tobacco smoke. Chest 1994;106:746-9.

23. Coultas DB. Health effects of passive smoking. 8. Passive smoking and risk of adult asthma and COPD: an update. Thorax 1998;53:381-7.

24. Radon K, Busching K, Heinrich J, et al. Passive smoking exposure: A risk factor for chronic bronchitis and asthma in adults? Chest 2002;122:1086-90.

25. Eisner MD, Klein J, Hammond SK, et al. Directly measured smoke exposure and asthma health outcomes. Thorax 2005;60:814-21.

26. Barone-Adesi F, Vizzini L, Merletti F, et al. Short-term effects of Italian smoking regulation on rates of hospital admission for acute myocardial infarction. Eur Heart J 2006;27:2468-72.

Correspondence to: Dr. Alisa Naiman, 491 Lawrence Ave. W., Ste. 101,TorontoON M5M 1C9; a.naiman@utoronto.ca

\section{In $\mathrm{MDD}$, do you compromise tolerability for efficacy?}

\section{Or do you aim for both?}

*Major depressive disorder

Wyeth 